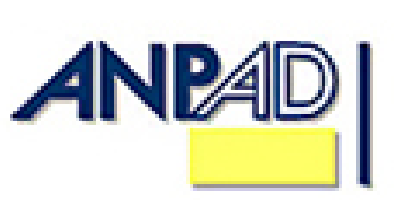

Disponível em

http://www.anpad.org.br/rac

RAC, Curitiba, v. 14, n. 3, art. 2,

pp. 414-433, Mai./Jun., 2010

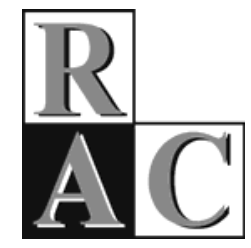

\title{
Relação entre Emendas Parlamentares e Corrupção Municipal no Brasil: Estudo dos Relatórios do Programa de Fiscalização da Controladoria-Geral da União
}

The relationship between amendments to the Federal Budget Law and municipal corruption in Brazil: evidence from reports of the Brazilian Internal Audit Agency

Antonio Carlos de Azevedo Sodré * Doutorando em Finanças, Massachusetts Institute of Technology, EUA.

Maria Fernanda Colaço Alves Doutoranda em Administração Pública, UnB. Analista de Finanças e Controle da Controladoria-Geral da União.

* Endereço: Antonio Carlos de Azevedo Sodré

MIT Sloan School of Management, 50 Memorial Drive, E52-416, Cambridge, MA 02142. E-mail: sodre@mit.edu

Copyright (C) 2010 RAC. Todos os direitos, inclusive de tradução, são reservados. É permitido citar parte de artigos sem autorização prévia desde que seja identificada a fonte. 


\title{
RESUMO
}

Estudos recentes sobre corrupção (Elliott, 2002; Klitgaard, 1988; Rose-Ackerman, 2002) indicam relação significativa entre transferência intergovernamental de recursos orçamentários via emendas parlamentares e incidentes de corrupção nas instâncias locais de governo. Quatro são as explicações, não excludentes, para a existência desta correlação: (i) aumento no ganho potencial do ato corrupto; (ii) aumento do poder discricionário local; (iii) aumento da pressão de rent-seekers e; (iv) conluio com corrupção federal. Utilizando dados do Programa de Fiscalização a partir de Sorteios Públicos da Controladoria-Geral da União, o presente trabalho busca estudar as relações existentes entre emendas parlamentares e os episódios de corrupção municipal no Brasil. A análise formal estatística, que utiliza uma série de variáveis de controle sociodemográficas e político-partidárias de interesse, sugere que, em média, municípios que recebem emendas parlamentares apresentam uma incidência 25\% maior de episódios de corrupção. Os resultados indicam que os eventos de corrupção municipal se correlacionam mais com o fato de o município receber ou não emendas parlamentares (quantidade de emendas) e menos com o volume de recursos repassados. Neste sentido, o estudo apontaria as explicações (iii) e (iv) para a questão central da pesquisa.

Palavras-Chave: corrupção; municípios; orçamento federal; emendas parlamentares.

\begin{abstract}
Previous studies on corruption (Elliott, 2002; Klitgaard, 1988; Rose-Ackerman, 2002) present the relationship between amendments and municipal corruption. Four nonexclusive explanations for the correlation are discussed: (i) the growing potential gains of corruption; (ii) the number of transactions under the control of the local government; (iii) the pressure from groups of private rent-seekers and; (iv) revenue transfers might be the result of collusion between local governments and federal congressmen. Using data from the Controladoria-Geral da União (Brazilian Internal Audit Agency) Anticorruption Program based on the random auditing of municipal government's expenditures, we study the relationship between amendments to the Brazilian Federal Budget Law and municipal corruption. On average, after controlling for a series of socio-economic and political variables, cities granted with revenue transfers derived from amendments have corruption rates that are $25 \%$ higher than the rest of the sample. Although our empirical results indicate that the increase in corruption occurs when the municipalities receive extraordinary revenue transfers, corruption seems to be insensitive to the amount of resources transferred. Such findings give more support to explanations (iii) and (iv).
\end{abstract}

Key words: corruption; municipalities; federal budget; budget amendments. 


\section{INTRODUÇÃO}

O tema corrupção tem justificadamente permeado cada vez mais as discussões sobre políticas públicas no Brasil. Nos últimos anos, não faltaram episódios de escândalos políticos envolvendo graves suspeitas de desvio de recursos em detrimento do interesse público, causando sério descrédito da população em relação à atuação do Estado e sua capacidade de controlar a gestão da coisa pública.

Tal tema deve, porém, ser analisado com cautela. A corrupção não é privativa do Brasil ou de países em desenvolvimento. Estudos recentes demonstram tratar-se de fenômeno decorrente, principalmente, de fragilidades institucionais, que prejudicam a accountability ou a efetividade do controle sobre a gestão pública.

Este estudo tem por objetivo analisar uma destas fragilidades institucionais brasileiras: a insuficiência de controle sobre a aprovação e execução de emendas parlamentares do orçamento federal. Esta falha resulta em distorção de um dos principais instrumentos de descentralização de recursos aos governos locais e corrobora com a persistência da corrupção no país.

Diversos episódios de escândalos recentes sugerem ligação entre transferências orçamentárias via emendas parlamentares e corrupção no Brasil. O escândalo dos chamados anões do orçamento foi um dos primeiros, após a promulgação da Constituição de 1988, a chamar a atenção para as fragilidades existentes na forma de confecção do orçamento federal por meio de emendas parlamentares.

Em 1993, o então chefe da Comissão do Orçamento do Congresso Nacional denunciou esquema de corrupção que envolveu parlamentares acusados de incluir emendas no Orçamento da União para enriquecimento ilícito. Por envolver, em sua maioria, parlamentares de pequena estatura, o escândalo ficou conhecido como anões do orçamento. As acusações incluíam o direcionamento de verbas para entidades filantrópicas ligadas a parentes e laranjas, e o recebimento de propina, por prefeituras e empreiteiras, para a inclusão de verbas orçamentárias para a realização de obras. As denúncias foram investigadas por Comissão Parlamentar Mista de Inquérito. Essa investigação resultou em seis parlamentares cassados, oito absolvidos e quatro que renunciaram ao mandato.

Caso mais recente reforça como ainda são extremamente frágeis suas formas de controle. Descoberto pela Controladoria-Geral da União [CGU] em 2006, a máfia das ambulâncias, como ficou conhecida, contava com uma quadrilha que negociava com congressistas a liberação de emendas destinadas a Municípios específicos, cujos prefeitos já haviam sido aliciados pelo grupo, para compra de ambulâncias. Tendo recursos garantidos, licitações municipais eram fraudadas e os preços superfaturados, gerando ganhos ilícitos ao parlamentar federal, aos dirigentes municipais e às empresas prestadoras de serviço. A Comissão Parlamentar de Inquérito formada investigou mais de 90 parlamentares envolvidos.

A despeito destes e outros diversos escândalos de corrupção brasileiros que poderiam ser citados, não há estabelecimento de uma relação precisa entre o fenômeno da corrupção e emendas parlamentares ao orçamento federal. A relação parece deixada ao campo da especulação e investigação de casos esporádicos, que são, muitas vezes, usados mais com intuito político-partidário do que como forma de aprimoramento da gestão pública.

Este estudo procura responder às seguintes questões: Qual a real relação entre emendas parlamentares ao orçamento e corrupção no âmbito municipal? Governos locais que recebem emendas tendem a ter uma gestão mais corrupta, ou todos os Municípios têm gestões similares e simplesmente aqueles que receberam emendas tem suas práticas indevidas mais evidenciadas, quando a corrupção vira escândalo a ser noticiado nos meios de comunicação de massa? Caso haja relação entre os fenômenos, quais as explicações possíveis?

Com base em amostra dos relatórios do Programa de Fiscalização a partir de Sorteios Públicos da Controladoria-Geral da União [CGU], e utilizando estatísticas descritivas, teste de hipótese para diferenças 
de médias e análises de regressão, são analisadas as relações existentes entre emendas parlamentares e episódios de corrupção no âmbito municipal.

A seção 2 apresenta os principais conceitos sobre corrupção. A seção 3 relaciona corrupção à gestão pública ineficiente e falta de accountability. A relação entre emendas parlamentares ao orçamento e o debate de quatro fatores que explicam, de forma não exaustiva, a relação entre corrupção e emendas são apresentados na seção 4. A escolha metodológica, os dados utilizados e os resultados da análise quantitativa são descritos nas seções 5 e 6 respectivamente. Por fim, a seção 7 apresenta as considerações finais do estudo.

\section{O FENÔMENO DA CORRUPÇÃO}

Usualmente entendida como abuso da função pública em benefício privado (Organização das Nações Unidas [ONU], 2003), ou ainda, séria violação de padrões ou expectativas associadas à administração pública (Johnston, 2002), a corrupção pública abrange atos como pagamento de obras com objeto inexistente, superfaturamentos, direcionamento de licitações, celebração de convênios irregulares, dentre muitas outras possibilidades. Seus custos mais graves não são necessariamente os subornos e propinas em si, mas as distorções decorrentes de negociações realizadas com recursos públicos que deixam em segundo plano o benefício social (Rose-Ackerman, 2002).

Publicação recente do Índice de Percepção da Corrupção da organização Transparência Internacional, que avalia a percepção de empresários e analistas de governo quanto à existência e ao grau de corrupção em diversos países, demonstra que o Brasil está atrás de países com igual ou pior indicadores de atividade econômica, como Uruguai, Colômbia, Cuba, Costa Rica e África do Sul (Lambsdorff, 2005). Mesmo considerando as corretas alegações de que a percepção de corrupção é afetada pela intensificação de seu combate, a pesquisa reitera a gravidade do problema no país.

Maior é esta gravidade quando se leva em conta que, quanto mais generalizada é a percepção de corrupção, maiores são os incentivos percebidos pelos indivíduos para se engajarem em atos corruptos (Cartier-Bresson, 1998). Além disso, ao favorecer os inescrupulosos e aqueles que dispõem de maior rede de contatos em detrimento daqueles que têm maior eficiência produtiva, a corrupção deforma os papéis alocativo e redistributivo do Estado, prejudicando sua legitimidade política (Rose-Ackerman, 2002).

Mauro (1995) sugere uma correlação negativa entre crescimento econômico nacional e altos índices de corrupção e outras medidas de ineficiência governamental. Embora a relação causal seja de difícil estabelecimento, há consenso entre pesquisadores e governantes de que o controle da corrupção é de extrema importância no desenvolvimento político, econômico e social.

Entretanto o mesmo consenso não se repete no que se refere a definições de políticas anticorrupção eficientes. Uma das causas deste fato está no pequeno número de pesquisas empíricas sobre o tema, capazes de dar clareza às causas e formas de manifestação da corrupção no país e, portanto, de melhor direcionar as políticas públicas sobre o assunto.

Embora haja poucas pesquisas empíricas rigorosas sobre o tema (Jos, 1993), houve, nos últimos anos, desenvolvimento de trabalhos diversos em busca da aferição indireta do impacto da corrupção (Bardhan, 1997). O avanço no refinamento dos estudos voltados ao marco teórico e às causas da corrupção, como foi desenvolvido por Treisman (2000), tem propiciado avanços no referencial para a reflexão sobre o impacto das estratégias desenvolvidas para sua prevenção e combate.

No Brasil, ainda são raros os estudos empíricos sobre o tema, apesar da evolução recente. Ferraz e Finan (2008) mostram que prefeitos municipais corruptos têm menores chances de se reelegerem. Weber (2006) e Zambioni Filho e Litschig (2006) documentam uma correlação negativa entre corrupção municipal e presença de associações comunitárias e Poder Judiciário respectivamente. Nenhum destes estudos, todavia, aponta a possível causa da corrupção. 


\section{CORRuPÇÃo E GeSTÃo PúblicA INEFICIENTE}

Conceito correlato à corrupção, porém não idêntico, é o de irregularidades de gestão, isto é, o menosprezo das legislações pertinentes e das boas práticas administrativas. As constatações de irregularidade são apontadas nos relatórios de fiscalização da Controladoria-Geral da União em Municípios brasileiros.

Dentre as irregularidades apontadas tem-se a comprovação de despesas com notas fiscais inidôneas, compras sem procedimento licitatório, realização de pagamentos indevidos, falta de controle dos beneficiários de programas sociais, pagamentos sem total realização do objeto, falta de divulgação de licitações e outros atos administrativos, falta de prestação de contas, entre muitas outras.

Tais irregularidades indicam a falta de controle sobre os recursos recebidos e despendidos. Demonstram, neste sentido, deficiências de accountability ou responsabilização horizontal, realizada por meio de controles recíprocos entre os poderes; e accountability vertical, relacionada ao controle dos cidadãos. Significa, portanto, falta de controle dos cidadãos e do próprio governo sobre os atos públicos e, por consequência, dificuldade de responsabilização dos agentes ímprobos (O’Donnell, 1998, 2005).

As deficiências podem ser decorrentes de disfunções gerenciais ou atos propriamente delituosos contra o erário público; ambos trazem prejuízo aos recursos públicos, mas diferenciam-se em relação à intencionalidade dos agentes. De qualquer forma, há que se perceber que a segunda hipótese raramente ocorre sem a primeira.

De forma exemplificativa, parece possível que uma compra sem licitação seja realizada numa situação emergencial, em que a gestão municipal avalie como melhor opção não cumprir a legislação no caso específico, mas garantir o suprimento do produto com presteza, em benefício da população.

Por outro lado, parece inteiramente factível também que a compra à revelia da legislação e, portanto, sem qualquer transparência ou prestação de contas satisfatória, se dê para beneficiar agentes públicos e privados, que negociam preços acima de mercado e desviam parte dos recursos para fins individuais.

Assim, compreende-se que nem todas as irregularidades de gestão possam ser denominadas corrupção propriamente dita, ou seja, atos deliberados de fraude e desvio de recursos. No entanto as irregularidades apontam falta de controle adequado da administração dos recursos municipais e descaso das boas práticas de gestão. Este descaso ou ineficiência na gestão acobertam a corrupção e com ela coadunam, quando não a incitam, porquanto, dificultam a accountability e facilitam a ação de agentes corruptores.

A falta de capacidade técnica das instâncias governamentais em promover uma gestão efetiva e bem controlada parece ainda mais evidente nas instâncias municipais, que possuem, em geral, quadro de servidores precário, ou seja, com menor capacitação e maior rotatividade.

Não obstante esta dificuldade operacional, parece claro também que políticos eleitos e servidores ansiosos por aproveitar-se de recursos públicos de forma ilegal se utilizam da falta de capacidade gerencial do Município como instrumento facilitador de transações ilícitas.

Assumindo-se alta correlação entre as possíveis causas da corrupção e grande dificuldade de verificação a priori da intencionalidade do agente, assume-se que ambas as disfunções podem ser entendidas como eventos de corrupção no sentido amplo para fins deste estudo.

Ainda assim, leve-se em consideração que, embora de forma lenta e gradual, as ferramentas de transparência, accountability e aprimoramento da gestão pública estão sendo cada vez mais difundidos não só no mundo (Pina \& Torres, 2003), mas também no país (Loureiro, Teixeira, \& Prado, 2008).

Esta tendência talvez possibilite, daqui a alguns anos, a diferenciação mais clara de intenção entre Municípios que têm uma gestão ineficiente, mas procuram aprimorar-se, daqueles que não demonstram tanto interesse em tornar sua gestão eficiente e transparente, porque se utilizam da ineficiência como ferramenta, ou ao menos escudo, para a realização de ações ilegais em benefício privado. 
De qualquer forma, tanto os riscos de ineficiência da gestão quanto da má fé de agentes podem ser mitigados por meio da manutenção de controles efetivos. Entende-se por controle efetivo aquele que fornece razoável segurança de execução da política pública de forma ordenada, ética, econômica, eficiente e efetiva. Isto significa que a gestão pública deve ter sempre em vista o cumprimento dos requisitos de prestação de contas, cumprimento dos normativos aplicáveis e salvaguarda de recursos, evitando-se perdas ou desperdícios (International Organization of Supreme Audit Institutions [INTOSAI], 2004).

\section{CORRUPÇÃo E EMENDAS PARLAMENTARES}

Emendas parlamentares são transferências intergovernamentais, ou seja, descentralizações de recursos federais, acrescidas à Lei Orçamentária Anual por solicitações de parlamentares individuais, bancadas ou comissões. Trata-se de despesas federais: (i) não-vinculadas, ou seja, de finalidade não previamente determinada; (ii) extraordinárias, ou seja, que não constituem um fluxo contínuo e; (iii) voluntárias ou negociáveis, discricionárias (Secretaria do Tesouro Nacional [STN], 2006).

Emendas parlamentares são, portanto, um instrumento constitucional (artigo 166, parágrafos $2^{\circ}$ a $4^{\circ}$ da Constituição da República Federativa do Brasil de 1988 (Constituição do Brasil, 2007)), que visa a inserir o Congresso Nacional nas discussões acerca do planejamento do orçamento federal e descentralizar voluntariamente recursos a instâncias locais com maior proximidade das demandas sociais.

Entretanto há posições dissonantes em relação à pertinência do instrumento. Alguns defendem irrestritamente a existência de emendas parlamentares como parte legítima de um sistema de representação democrática, buscando evitar que o poder legislativo tenha papel meramente coadjuvante na definição da peça mais importante do planejamento federal.

Outros ressaltam a necessidade de descentralização de recursos em si, uma vez que os Municípios brasileiros são, em última instância, os responsáveis pelo bem-estar e qualidade de vida da população que neles reside. Sobre eles recai uma ampla gama de demandas sociais que contrasta com a distribuição pouco descentralizada da arrecadação nacional, na qual os Municípios ficam com a menor parcela. Neste sentido, a obtenção de recursos complementares seria vital à gestão local.

Por outro lado, há argumentos pela extinção das emendas parlamentares, justificados pela dificuldade de fiscalização e grande quantidade de escândalos sobre malversação dos recursos advindos de emendas nas últimas décadas. Pires (2005) estuda os incentivos ao uso de emendas parlamentares individuais no Brasil como moeda de troca de favores entre os poderes executivo e legislativo federais, muitas vezes em detrimento do interesse público.

Posições mais moderadas entendem a importância do instrumento, tanto pela participação do Congresso no planejamento federal quanto pela necessidade de descentralização de recursos; no entanto defendem o aumento da transparência e do controle das emendas parlamentares. Não há consenso, porém, sobre a forma ou estrutura de controle necessária.

Neste trabalho especula-se que uma das causas que contribuem para o aumento da corrupção é a existência de transferências de recursos financeiros federais na forma de emendas parlamentares sem o devido controle da sua gestão, configurando grave falha institucional.

É sabida a existência de inúmeras formas de irregularidades e corrupção atreladas a emendas parlamentares, conforme episódios já ressaltados neste estudo. Pesquisa realizada por Fleischer e Manzeti e Blake sugere que, durante o mandato do presidente Collor de Mello, as comissões ilícitas derivadas de contratos públicos cresceram de 10 a 15\% para 30 a 50\% no país (Rose-Ackerman, 2002). Muito provavelmente boa parte destes contratos públicos derivou de emendas orçamentárias.

Por outro lado, ao contrário do que possa transparecer, relacionar a questão da corrupção às emendas parlamentares para além da especulação não é um assunto trivial. Corrupção e escândalo são coisas 
totalmente diferentes e ambas podem ocorrer uma na ausência da outra, muitas vezes com intuito politizado controverso (Johnston, 2002).

A interface dos setores público e privado sucita diversas oportunidades de ganhos econômicos advindos de atos corruptos. Segundo Rose-Ackerman (2002), a incidência e o nível de corrupção dependem basicamente de três pontos principais: benefício potencial do ato para o transgressor, o risco de ser descoberto e punido e o poder relativo entre corruptores e corrompidos.

Klitgaard (1988) resume bem o que considera aspectos-chave da corrupção: (i) monopólio, ou seja, baixa competição entre setor público e privado e mesmo dentro dos setores: competição política no público; competição econômica no privado; (ii) poder, entendido como o poder discricionário dado aos servidores públicos e políticos; (iii) prestação de contas, que se refere às formas de controle e fiscalização a que os atos de governo estão sujeitos.

Unindo os conceitos de Rose-Ackerman (2002) e Klitgaard (1988), Elliott (2002) acrescenta ainda que a corrupção entre servidores públicos não elegíveis e agentes privados tende a ser menor do que quando envolve agentes políticos elegíveis.

Assim, tomando por base estes estudos, foi possível identificar pelo menos quatro fatores causais, não excludentes entre si, que racionalizam uma estreita relação entre corrupção municipal e recebimento de recursos federais voluntários via emendas parlamentares, e que potencialmente apoiam os resultados empíricos apresentados neste estudo.

\section{Aumento no Ganho Potencial do Ato Corrupto}

Para determinada faixa de recursos envolvidos ou de quantidade de transações corruptas necessárias, o risco do negócio corrupto é o mesmo, visto que a probabilidade de ser pego e as possíveis punições podem ser pensadas como razoavelmente constantes.

Em outras palavras, no Brasil, incrementos no ganho potencial do ato corrupto não são necessariamente acompanhados por um aumento da punição aos envolvidos caso o ato seja descoberto. Assim, um ato corrupto compensa mais quanto maior forem os recursos envolvidos e, portanto, maior a possibilidade de remuneração dos participantes. Além disso, a ampliação de recursos disponíveis pode aumentar o número de transações entre o setor público e o privado, ampliando a possibilidade de atos irregulares.

Emendas parlamentares implicam recursos voluntários extras para os governos locais. Caso os gestores recebam estes recursos, mas não tenham a obrigação de manter o devido acompanhamento nem sofram ameaças críveis de que haverá fiscalização eficiente, estes verão aumentada em muito sua tentação à corrupção.

\section{Aumento do Poder Discricionário Local}

O recebimento de recursos extras gera aumento no poder discricionário do gestor. Afinal, este terá um montante maior para aplicar na compra de bens ou na contratação de serviços e terá que, discricionariamente, determinar quais serão os contratados, isto é, os receptores finais dos recursos federais.

Grande parte dos Municípios brasileiros tem recursos humanos pouco qualificados e práticas ruins de gestão que não primam pela competência e pelo controle interno da administração. Desta feita, o aumento do poder discricionário, sem a devida assistência quanto à melhor forma de sua aplicação e sem o controle necessário, tende a gerar corrupção e ineficiência crescentes no governo local. 


\section{Aumento de Pressão de Rent-seekers}

O aumento de recursos municipais está associado a uma maior quantidade de bens e serviços a serem adquiridos para repasse à população, tais como a construção de uma escola ou a compra de equipamentos hospitalares.

A administração municipal passa então a ser pressionada pelo mercado ofertante destes bens e serviços, principalmente quando se trata de grandes organizações ofertantes, tais como grandes empresas empreiteiras. É possível que estas, sabendo da existência do repasse extraordinário de recursos, busquem cooptar a administração local para extrair renda ilícita. Por exemplo, uma das formas de pressão é o oferecimento de vantagens indevidas aos gestores locais para que determinada empresa vença a competição pelo fornecimento de determinado bem, ou para que o preço do serviço seja superfaturado etc.

Há ainda outras razões para o pagamento de suborno: incluir determinada empresa no rol de habilitados a licitar, organizar especificações de produtos e serviços que favoreçam um fornecedor específico na licitação, autorizar cobrança de preços inflacionados dos usuários de serviços, diminuir os requisitos de qualidade e segurança do produto ou serviço prestado, dentre outras (Rose-Ackerman, 2002).

\section{Conluio com a Corrupção Federal}

Os recursos das emendas podem ser fruto de corrupção em âmbito federal. Neste caso, os parlamentares corruptos tenderão a escolher os Municípios que receberão emendas a partir da análise da gestão que tem maior propensão a participar do conluio (isto é, aceitar participar de esquema ilícito), seja porque a gestão local é sabidamente corrupta seja porque é despreparada.

Exemplificativamente, quando um parlamentar coopta determinada empresa corruptora para executar uma obra em determinada localidade com recursos de emendas destinadas a um Município, é factível que esta administração local se deva coadunar com o ato corrupto praticado. Somente desta forma será possível garantir que tal empresa vencerá uma possível licitação.

Tal empresa contratada poderia cobrar preços superfaturados, economizar em itens de qualidade, dentre outras possibilidades de atos ilícitos, de forma a retirar dali os recursos necessários para pagamento de propinas aos agentes públicos envolvidos. Isto somente seria possível com a anuência dos agentes municipais responsáveis pelo controle primário do repasse, seja porque estes deliberadamente concordam com o fato ou porque têm uma gestão pública falha que não é capaz de identificar o desvio iminente.

\section{ANÁLISE EMPÍRICA}

Este estudo investiga a relação entre emendas parlamentares e corrupção por meio de pesquisa empírica na qual foram analisados 240 Municípios. A indicação de grau de corrupção municipal, obtida por meio dos Relatórios de Fiscalização produzidos em 2006 e 2007 pelo Programa de Fiscalização a partir de Sorteios Públicos da CGU, foi comparada ao recebimento ou não de emendas parlamentares nos dois anos anteriores à fiscalização. A comparação foi realizada por meio da análise descritiva dos dados, de teste de hipótese para diferenças de médias e de análise de regressão.

Os itens seguintes desta seção descrevem em detalhe os dados da corrupção municipal, recebimento de emendas parlamentares e outros dados relevantes.

\section{Dados sobre a corrupção municipal}

O programa de fiscalização da CGU, instituído em 2003, avalia a gestão de recursos públicos federais repassados a Municípios, evidenciando possíveis irregularidades de gestão e indícios de desvio de recursos 
(CGU, 2006). A escolha dos Municípios é feita aleatoriamente por meio do mecanismo de sorteio utilizado pela Caixa Econômica Federal para loterias federais, eliminando possíveis vieses amostrais decorrentes de eventual ligação entre a execução de auditorias e o recebimento de emendas parlamentares. A cada evento de sorteio são identificados 60 Municípios com até 500 mil habitantes a serem fiscalizados.

Nos municípios de até 20 mil habitantes são analisados os recursos relacionados a todas as áreas programáticas do governo, enquanto em Municípios entre 20 e 500 mil habitantes são analisadas as áreas de Educação, Assistência Social e Saúde, além de duas outras sorteadas em cada evento (CGU, 2006).

Todas as informações referentes a repasses de verbas federais à localidade, além de informações sobre convênios firmados, denúncias recebidas e suspeitas de irregularidades apontadas pela mídia são levantadas previamente. As ações de fiscalização em campo (na localidade) duram em média uma semana; em geral, analisam recursos repassados nos dois últimos exercícios financeiros.

Os analistas de finanças e controle da CGU, após levantamento junto à população local sobre indícios de práticas irregulares, iniciam a análise de convênios, licitações, notas fiscais de compras, inspeção física de obras realizadas, funcionamento de órgãos de controle tais como o Conselho de Educação, entrevistas do público beneficiário de alguns programas de governo, entre outras verificações (CGU, 2006). No final do processo, é produzido um Relatório de Fiscalização de cada Município, que contém todas as constatações de irregularidades encontradas.

O fato de o universo do Programa de Fiscalização contemplar somente Municípios de pequeno e médio porte (até 500 mil habitantes) causa impacto positivo à pesquisa, visto que neste universo amostral o efeito renda das emendas parlamentares recebidas é maior e de mais fácil percepção.

Para esta pesquisa foram analisados, na íntegra, os 240 Relatórios de Fiscalização produzidos pelos $20^{\circ}$, $21^{\circ}, 22^{\circ}$ e $23^{\circ}$ Sorteios realizados em 2006 e 2007. Relatórios anteriores não foram utilizados por conter metodologias diferentes de apresentação de medidas de corrupção, sem quantificação e tipificação de constatações, o que impossibilita uma análise comparativa.

A quantidade de constatações de irregularidade, quantidade de problemas administrativos e a quantidade de problemas graves são utilizadas neste estudo como medida de corrupção na gestão municipal.

Embora não haja diferenciação formalizada pela instituição de controle entre problemas administrativos e graves, a análise dos relatórios evidencia que problemas administrativos são aqueles em que resta bem evidenciado o descumprimento de obrigações legais quanto à formalização de processos, documentação de contratos e pagamentos etc., ou ainda problemas relacionados ao questionamento da eficiência administrativa. Em termos gerais, trata-se de problemas que devem ser sanados em prol da eficiência administrativa e como facilitador do controle, mas que não constituem casos de prejuízo ao erário.

Já os problemas graves são aqueles que envolvem indícios de prejuízos e fraudes decorrentes de atos impróprios, tais como licitações forjadas, superfaturamento de despesas, objetos inexistentes etc.

Como mostra a Tabela 1, em média, o número de constatações foi de 53,73 por município (mediana 45,5), o número de problemas graves foi de 5,73 (mediana 2) e o número de problemas administrativos foi de 15,01 (mediana 9). 
Tabela 1

Estatísticas Descritivas - Corrupção, Emendas Parlamentares e Índices Sócio-demográficos

\begin{tabular}{|c|c|c|c|c|c|}
\hline & Média & $\begin{array}{l}\text { Desvio- } \\
\text { Padrão }\end{array}$ & Mediana & Mínimo & Máximo \\
\hline \multicolumn{6}{|l|}{ Corrupção } \\
\hline Constatações & 53,75 & 34,04 & 45,5 & 3 & 249 \\
\hline Problemas Graves & 5,73 & 8,49 & 2 & 0 & 47 \\
\hline Problemas Administrativos & 15,01 & 16,64 & 9 & 0 & 109 \\
\hline Recursos Federais Auditados (R\$mil) & $6.720,44$ & $14.000,00$ & $2.970,29$ & 52,67 & $171.000,00$ \\
\hline \multicolumn{6}{|l|}{ Emendas Parlamentares } \\
\hline Recursos Autorizados (R\$mil) & 665,92 & $3.221,83$ & 80,00 & 0 & $3.350,00$ \\
\hline Recursos Liquidados (R\$mil) & 492,21 & $2.127,16$ & 20,00 & 0 & $1.930,00$ \\
\hline \multicolumn{6}{|l|}{ Variáveis Sociodemográficas } \\
\hline População (milhares) & 26,75 & 60,68 & 10,04 & 7,95 & 461,53 \\
\hline Índice de Desenvolvimento Humano & 0,69 & 0,08 & 0,70 & 0,51 & 0,84 \\
\hline Índice de Desenvolvimento Humano (Educação) & 0,78 & 0,09 & 0,79 & 0,58 & 0,94 \\
\hline Índice de Desenvolvimento Humano (Longevidade) & 0,71 & 0,08 & 0,71 & 0,51 & 0,88 \\
\hline Índice de Gini & 0,56 & 0,06 & 0,56 & 0,43 & 0,73 \\
\hline Intensidade de Pobreza & 53,18 & 9,94 & 53,73 & 21,69 & 82,01 \\
\hline Percentual de Pobreza (\%) & 48,86 & 22.34 & 50.33 & 8.34 & 86,97 \\
\hline Renda Per Capita (R\$) & 159,22 & 89,47 & 141,69 & 44,09 & 503,34 \\
\hline \multicolumn{6}{|l|}{ Competições Políticas } \\
\hline $\begin{array}{l}\text { Percentual de Votos do Atual Prefeito nas Eleições } \\
\text { de } 2004 \text { ( } 1^{\circ} \text {. Turno) }\end{array}$ & 54,76 & 11,81 & 53,21 & 29,53 & 100 \\
\hline
\end{tabular}

Nota. Fonte. Corrupção: fiscalizações de 03/2006 a 05/2007 (Controladoria-Geral da União. (2007). Relatórios de fiscalização de sorteios de municípios no 742 a 964. [Relatório Técnico]. Brasília: Secretaria Federal de Controle Interno. Recuperado em 11 novembro, 2007, de http://www.cgu.gov.br/sorteios/index1.asp). Emendas parlamentares: emendas à LOA em 2004 a 2006, sob modalidade de aplicação 40 (Senado Federal. (2008). LOA - 2005/2006/2007 - Execução de emendas por localidade. Brasília: Senado Federal. Recuperado em 5 fevereiro, 2008, de http://www8.senado.gov.br/businessobjects/enterprise115/desktoplaunch/InfoView/main/headerPlus.do?objId=0). Índice de Desenvolvimento Humano: 2000 (Programa das Nações Unidas para o Desenvolvimento. (2003). Atlas do desenvolvimento humano no Brasil - Municipal 1991 e 2000. [Relatório Técnico]. Brasília: PNUD. Recuperado em 5 fevereiro, 2008, de http://www.pnud.org.br/atlas/tabelas/). População: 2000 (Instituto Brasileiro de Geografia e Estatística. (2001). Censo demográfico 2000. [Relatório Técnico]. Rio de Janeiro: IBGE. Recuperado em 2 fevereiro, 2008, de http://www.ibge.gov.br/cidadesat/topwindow.htm?1). Renda per capita: 2004 e demais variáveis sociodemográficas: 2003 (Instituto Brasileiro de Geografia e Estatística. (2003) Mapa de pobreza e desigualdade - Municípios brasileiros - 2003. [Relatório Técnico]. Rio de Janeiro: IBGE. Recuperado em 2 fevereiro, 2008, de http://www.ibge.gov.br/cidadesat/topwindow.htm?1). Competições Políticas (Instituto Brasileiro de Geografia e Estatística. (2004). Representação política - 2004. [Relatório Técnico]. Rio de Janeiro: IBGE. Recuperado em 2 fevereiro, 2008, http://www.ibge.gov.br/cidadesat/topwindow.htm?1).

A Figura 1 demonstra que 66\% dos Municípios fiscalizados têm entre 20 e 50 constatações de corrupção, enquanto aqueles que receberam menos de 20 ou mais de 80 constatações não ultrapassam $15 \%$ dos casos. 

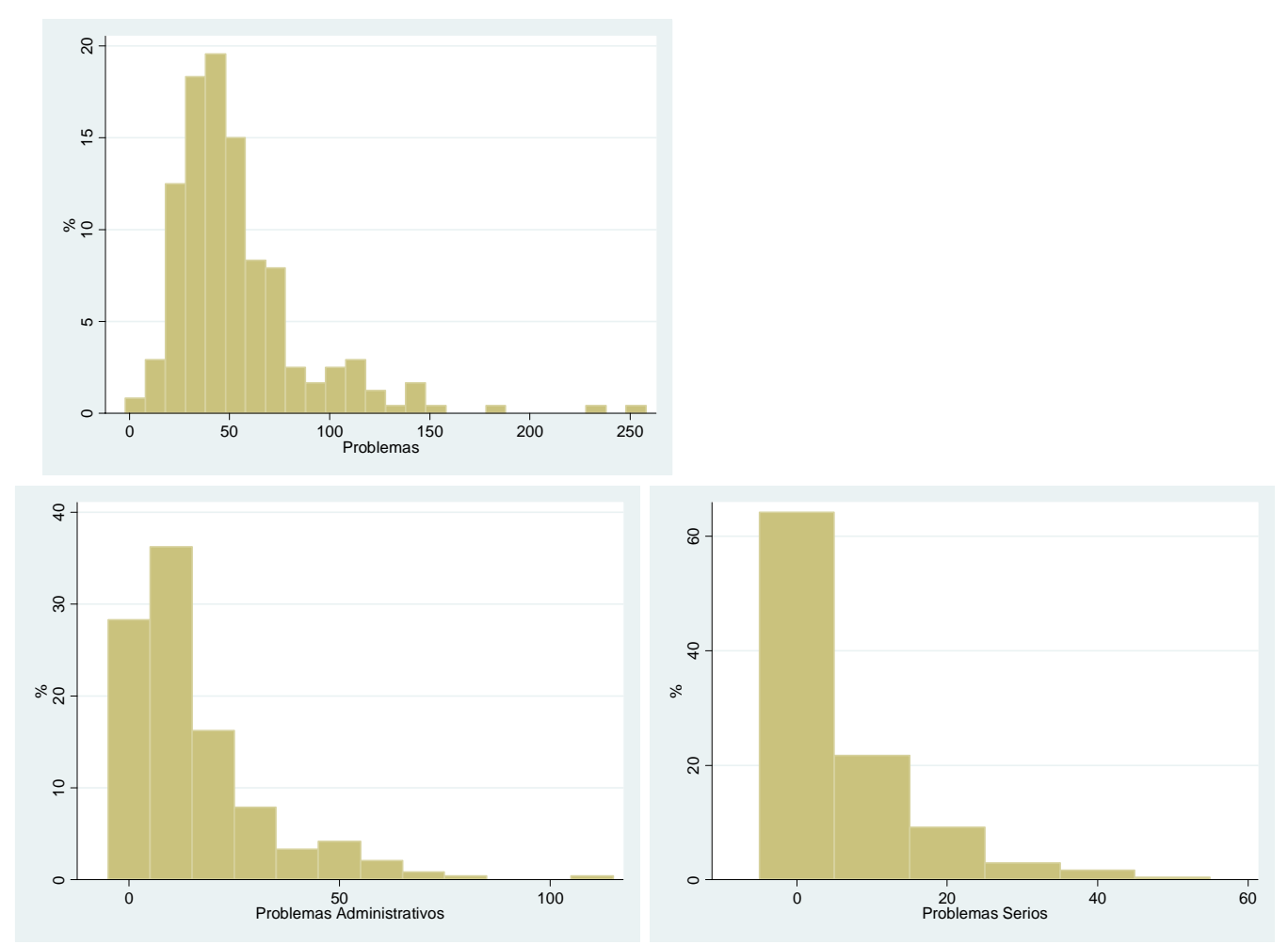

Figura 1. Histogramas - Variáveis: Medidas de Corrupção

Fonte: Fiscalizações de 03/2006 a 05/2007 (Controladoria-Geral da União. (2007). Relatórios de fiscalização de sorteios de municípios no 742 a 964. [Relatório Técnico]. Brasília: Secretaria Federal de Controle Interno. Recuperado em 11 novembro, 2007, de http://www.cgu.gov.br/sorteios/index1.asp).

Grande parte das constatações, porém, não se encontra classificada entre problemas administrativos ou graves, porque a orientação do órgão de fiscalização é de que esta classificação somente deve ser indicada quando houver razoável certeza pelo auditor de tratar-se de um caso de irregularidade formal (problema administrativo), ou de fraude e desvio planejado (problema grave).

Há, portanto, constatações que envolvem questões de falha institucional, constatações entendidas em princípio como mais significativas ou graves do que irregularidades formais (problemas administrativos) e menos graves do que atos dolosos contra a administração pública (problemas graves).

A figura 1 demonstra que mais de 80\% dos Municípios receberam entre 0 e 20 constatações de problemas administrativos e mais de $90 \%$ receberam entre 0 e 20 constatações de problemas graves. Logo, a distribuição das variáveis problemas graves e problemas administrativos na amostra é muito mais concentrada em valores abaixo de 20 do que a variável quantidade de constatações. Nota-se que 78 (32,5\%) dos Municípios não tiveram nenhum problema grave identificado e 29 (7\%) não apresentaram nenhum problema administrativo. Nenhum dos Municípios da amostra deixou de apresentar constatação de irregularidade.

\section{Dados sobre Emendas Parlamentares}

Os dados sobre a formulação e execução das emendas orçamentárias foram extraídos do Sistema Siga Brasil, disponibilizado pelo Senado Federal, que reúne informações de diversas bases de dados sobre planos e orçamentos públicos, incluindo o Sistema Integrado de Administração Financeira do Governo Federal [SIAFI].

São consideradas emendas parlamentares a municípios todas as emendas à LOA propostas por comissão, bancada ou parlamentares individuais aplicadas como transferências diretas a municípios (modalidade de aplicação 40). Constituem a amostra todas as emendas parlamentares autorizadas para os exercícios orçamentários de dois anos anteriores à fiscalização, pertencendo, portanto, ao período de análise da CGU. 
Para municípios sorteados em 2006, coletaram-se os dados de emendas referentes a 2004 e 2005. Para municípios sorteados em 2007, coletaram-se os mesmos dados referentes a 2005 e 2006.

As emendas foram consideradas conforme dois diferentes status. O primeiro considera todas as emendas autorizadas na LOA. O segundo status exclui aquelas emendas autorizadas mas não executadas no orçamento, considerando para este fim a sua liquidação.

Portanto a análise considera a variável valor autorizado das emendas como o montante da dotação efetivamente aprovado pelo Congresso Nacional e pelo Poder Executivo. Já a variável valor liquidado considera o valor orçamentário comprometido, independentemente do valor autorizado inicialmente e de outros recursos destinados à mesma classificação funcional-programática. Neste último caso o intuito é diferenciar os valores aprovados daqueles recursos que potencialmente foram repassados à gestão municipal.

Assim, entre os 240 Municípios da amostra, 120 (50\%) receberam emendas (sob o status liquidado) em pelo menos um dos dois anos antes da fiscalização. Uma importante característica dos dados é que, em média, o valor dos recursos federais liquidados, via emenda nos dois anos anteriores ao sorteio, é relativamente pequeno em comparação com recursos federais auditados pela CGU. Como indicado na Tabela 1, enquanto a média dos recursos autorizados (liquidados) foi de R\$ 665,92 mil (R\$ 492,21 mil), a média dos recursos federais fiscalizados pelas auditorias atingiu $\mathrm{R} \$ 6.720,44$ mil.

Considerando apenas as municipalidades que receberam pelo menos uma emenda no biênio anterior à fiscalização, os municípios receberam, em média, 3,72 emendas, no valor total médio de R\$984,44, quantia correspondendo a aproximadamente $\mathrm{R} \$ 30,65$ por habitante.

\section{Outros Dados}

Em adição às variáveis de repasse de recursos via emenda parlamentar e de corrupção discutidas anteriormente, foi coletada uma série de variáveis sociodemográficas (Índice de Desenvolvimento Humano e seus componentes, intensidade de pobreza, percentual de pobres na população, Índice de Gini municipal e renda per capita) e variáveis relacionadas com o nível de competição político-partidária municipal (percentual de votos válidos recebidos pelo prefeito nas eleições de 2004 e partido do prefeito). A Tabela 1 também mostra as estatísticas descritivas para as variáveis de controle coletadas.

Estas variáveis são utilizadas nas análises de regressão discutidas a seguir para controlar fatores correlacionados com o recebimento de emendas parlamentares e o nível de corrupção. Por exemplo, seria natural que os congressistas buscassem alocar recursos federais via emendas parlamentares para localidades mais pobres e de menor desenvolvimento social. No entanto também é razoável pensar que Municípios com gestores corruptos tendam a ser mais pobres. Caso esta relação fosse desconsiderada nas análises, os resultados obtidos poderiam ser viesados.

Da mesma maneira, pode-se conjecturar que um menor nível de competição municipal esteja relacionado com o nível de corrupção da gestão local. Quanto menor a ameaça de outros partidos ou grupos políticos ao atual prefeito, menor a pressão da oposição em fiscalizar os atos da administração municipal. Adicionalmente, se recursos federais, advindos de emendas no orçamento, potencialmente podem ajudar o grupo político atualmente detentor da administração municipal a manter-se no poder, então congressistas, de acordo com suas alianças locais, poderiam lutar para que emendas sejam enviadas para municípios nos quais a posição dos seus aliados políticos é constantemente ameaçada pela ação de grupos políticos rivais.

\section{RESULTADOS}

A análise estatística é baseada em testes de hipótese para diferença de médias e análises de regressão. A amostra foi dividida em 2 grupos. Em cada caso, a média e o desvio-padrão das variáveis número de 
constatações, problemas administrativos e problemas graves de cada grupo foram estimados e o seguinte teste de hipóteses foi conduzido:

$$
H_{0}=\mu_{1}-\mu_{2}=0 \underset{\text { vs. }}{ } H_{1}=\mu_{1}-\mu_{2}>0
$$

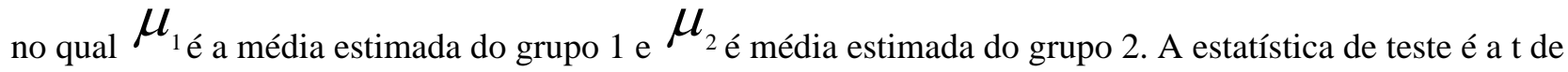
Student com n-1 graus de liberdade (onde n é o número total de observações nos dois grupos).

Primeiramente, a amostra foi dividida em Municípios que não receberam nenhuma emenda em 2004/05 ou 2005/06 (Grupo 2) e Municípios que receberam pelo menos uma emenda em 2004/05 ou 2005/06 (Grupo 1). A Tabela 2 mostra que Municípios que receberam emendas nos dois anos anteriores à fiscalização receberam, em média, $25 \%$ a mais de constatações, além de $49 \%$ a mais de problemas graves e $26 \%$ a mais de constatações de problemas administrativos.

Tabela 2

Testes de Hipóteses e Estatísticas Descritivas: Municípios que Receberam Emendas vs. Municípios que não Receberam

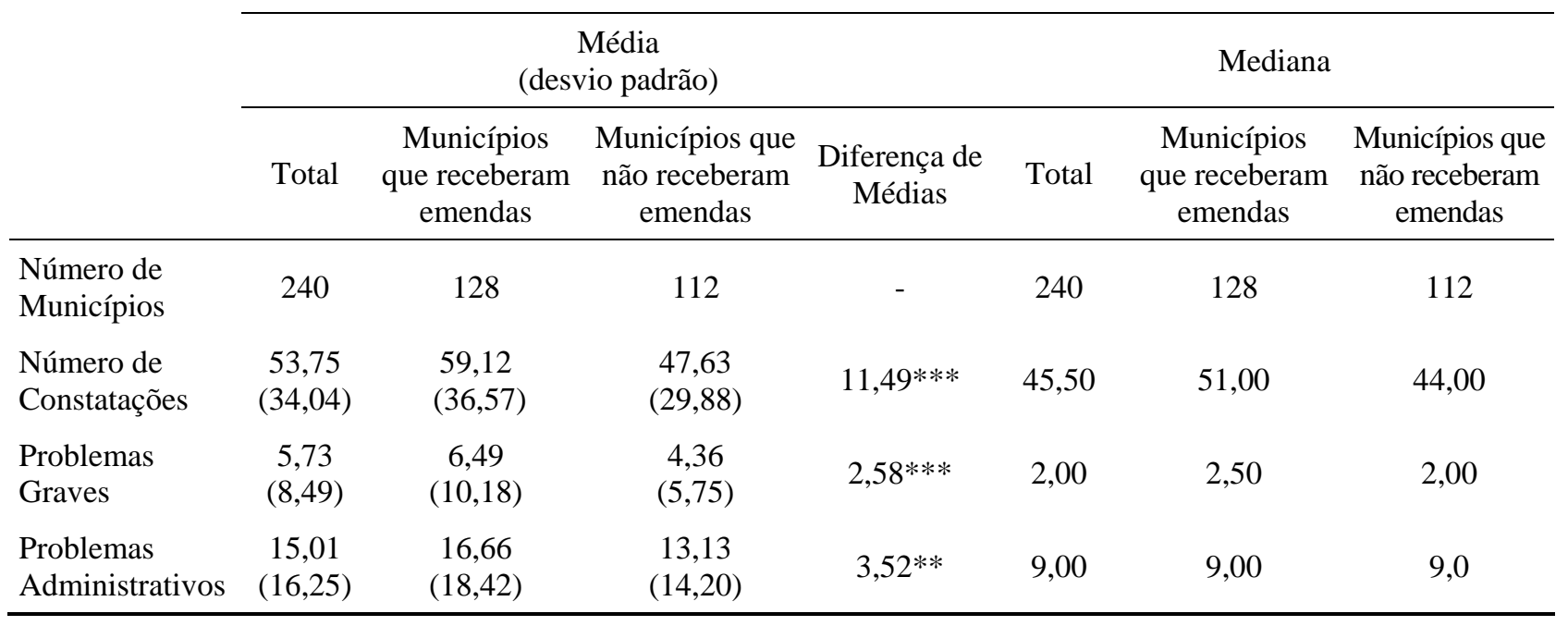

Nota. Fonte. Número de constatações, problemas graves e problemas administrativos: fiscalizações de 03/2006 a 05/2007 (Controladoria-Geral da União. (2007). Relatórios de fiscalização de sorteios de municípios $\mathrm{n}^{\circ} 742$ a 964 . [Relatório Técnico]. Brasília: Secretaria Federal de Controle Interno. Recuperado em 11 novembro, 2007 de http://www.cgu.gov.br/sorteios/index1.asp). Emendas parlamentares: emendas à LOA em 2004 a 2006, sob modalidade de aplicação 40 (Senado Federal. (2008). LOA 2005/2006/2007 - Execução de emendas por localidade. Brasília: Senado Federal. Recuperado em 5 fevereiro, 2008, de http://www8.senado.gov.br/businessobjects/enterprise115/desktoplaunch/InfoView/main/headerPlus.do?objId=0).

Teste t de Hipótese para igualdade de médias: *** rejeita-se a hipótese nula de que as médias são iguais a $1 \%$ de significância, ** rejeita-se a hipótese nula de que as médias são iguais a 5\% de significância e *rejeita-se a hipótese nula de que as médias são iguais a $10 \%$ de significância.

Em Municípios que não receberam emendas foi observado, em média, 11,49 constatações, 3,52 problemas administrativos e 2,56 problemas graves a menos que municípios que receberam pelo menos uma emenda. Para a variável quantidade de constatações e problemas graves, rejeita-se a hipótese nula de que as médias dos dois grupos são iguais com 99\% de confiança e, no caso das constatações de problemas administrativos rejeita-se a mesma hipótese com 95\% de confiança.

A análise foi estendida para verificar se a quantidade de recursos recebidos afeta a propensão à corrupção. Ressalta-se que algumas explicações para a existência de relação entre recebimento de emendas e corrupção, em discussão neste trabalho, especialmente o aumento do poder discricionário local e o aumento da pressão de rent-seekers, casos relevantes, não são discrepantes com uma relação positiva entre recursos descentralizados via emendas e corrupção. 
Ao se definir o Grupo 1 como Municípios que receberam mais de uma emenda e Grupo 2 aqueles que receberam uma ou nenhuma emenda e efetuar o teste de hipótese para diferença de médias, a diferença de médias se mantém com pelo menos 5\% de significância.

Todavia, dividindo a amostra entre Municípios que recebem mais de R 224 mil em emendas (mediana da variável valor pago em emendas) como Grupo 2 e o resto da amostra como Grupo 1 e efetuando o teste de hipótese descrito em (1) para as variáveis de corrupção, os resultados para diferença de média não se mantém. O mesmo se repete ao delimitar como Grupo 2 os Municípios que receberam valores per capita de emendas acima de $\mathrm{R} \$ 18,09$ e como Grupo 1 o restante da amostra (Tabela 3).

Tabela 3

Testes de Hipóteses: Análise de Sensitividade

Média (desvio padrão)

Total Municípios Municípios Diferença Municípios Municípios Diferença Municípios Municípios Diferença que que de que que de que que de receberam receberam Médias receberam receberam Médias receberam receberam Médias mais de 1 mais de menos de mais de menos de emenda emendas $\quad \mathrm{R} \$ 224$ mil $\dagger \mathrm{R} \$ 224$ mil $\dagger \quad \mathrm{R} \$ 19,04 \pm \quad \mathrm{R} \$ 19,04 \pm$ em emendas em emendas per capita per capita em emendas em emendas

\begin{tabular}{|c|c|c|c|c|c|c|c|c|c|c|}
\hline Observações & 240 & 84 & 156 & - & 60 & 180 & - & 61 & 179 & - \\
\hline $\begin{array}{l}\text { Número de } \\
\text { Constatações }\end{array}$ & $\begin{array}{c}53,75 \\
(34,04)\end{array}$ & $\begin{array}{c}60,38 \\
(38,09)\end{array}$ & $\begin{array}{c}50,19 \\
(31,19)\end{array}$ & $10,16^{* *}$ & $\begin{array}{c}62,02 \\
(42,48)\end{array}$ & $\begin{array}{c}51,00 \\
(30,36)\end{array}$ & $11,02 *$ & $\begin{array}{c}59,72 \\
(41,46)\end{array}$ & $\begin{array}{c}51,72 \\
(30,98)\end{array}$ & 8,00 \\
\hline $\begin{array}{l}\text { Problemas } \\
\text { Graves }\end{array}$ & $\begin{array}{c}5,73 \\
(8,49)\end{array}$ & $\begin{array}{c}7,61 \\
(10,30)\end{array}$ & $\begin{array}{c}4,72 \\
(7,16)\end{array}$ & $2,88^{*}$ & $\begin{array}{c}6,52 \\
(9,13)\end{array}$ & $\begin{array}{c}5,47 \\
(8,27)\end{array}$ & 1,04 & $\begin{array}{c}5,82 \\
(8,68)\end{array}$ & $\begin{array}{c}5,70 \\
(8,44)\end{array}$ & 0,12 \\
\hline $\begin{array}{l}\text { Problemas } \\
\text { Administrativos }\end{array}$ & $\begin{array}{c}15,01 \\
(16,65)\end{array}$ & $\begin{array}{c}17,76 \\
(16,74)\end{array}$ & $\begin{array}{c}13,56 \\
(16,46)\end{array}$ & $4,23 *$ & $\begin{array}{c}18,88 \\
(18,12)\end{array}$ & $\begin{array}{c}13,72 \\
(15,97)\end{array}$ & $4,23 *$ & $\begin{array}{c}15,86 \\
(17,20)\end{array}$ & $\begin{array}{c}14,72 \\
(16,49)\end{array}$ & 0,94 \\
\hline
\end{tabular}

Nota. Fonte. Número de constatações, problemas graves e problemas administrativos: fiscalizações de 03/2006 a 05/2007 (Controladoria-Geral da União. (2007). Relatórios de fiscalização de sorteios de municípios $\mathrm{n}^{\circ} 742$ a 964. [Relatório Técnico]. Brasília: Secretaria Federal de Controle Interno. Recuperado em 11 novembro, 2007 de http://www.cgu.gov.br/sorteios/index1.asp). Emendas parlamentares: emendas à LOA em 2004 a 2006, sob modalidade de aplicação 40 (Senado Federal. (2008). LOA 2005/2006/2007 - Execução de emendas por localidade. Brasília: Senado Federal. Recuperado em 5 fevereiro, 2008, de http://www8.senado.gov.br/businessobjects/enterprise115/desktoplaunch/InfoView/main/headerPlus.do?objId=0). População: 2000 (Instituto Brasileiro de Geografia e Estatística. (2001). Censo demográfico 2000. [Relatório Técnico]. Rio de Janeiro: IBGE. Recuperado em 2 fevereiro, 2008, de http://www.ibge.gov.br/cidadesat/topwindow.htm?1).

Teste $\mathrm{t}$ de Hipótese para igualdade de médias: *** rejeita-se a hipótese nula de que as médias são iguais a $1 \%$ de significância, ** rejeita-se a mesma hipótese nula a 5\% de significância e *rejeita-se a mesma hipótese nula $10 \%$ de significância. $†$ Valor mediano ( \pm Valor mediano per capita) do repasse via emendas, considerando apenas os municípios que receberam pelo menos uma emenda.

A análise de diferenças de médias indica que Municípios que recebem emendas parlamentares tendem a ter mais episódios de corrupção; todavia a quantidade de recursos liquidados não parece afetar significativamente o nível de corrupção. Tal conclusão é corroborada pela análise de regressão, que apresentamos abaixo.

Para cada variável de corrupção (quantidade de constatações, problemas graves e problemas administrativos), estimou-se seguinte modelo de regressão linear,

$$
\text { corrupcao }_{i}=\alpha_{0}+\alpha_{1} \times \text { emend }_{i}+\eta \times \text { controles }_{i}+\varepsilon_{i}
$$

no qual corrupção equivale a uma das medidas de corrupção no Município i, emenda é uma medida associada ao recebimento de emendas pelo Município i e $\varepsilon_{i}$ é o componente aleatório. Utilizam-se duas medidas associadas ao recebimento de emendas: (i) uma variável categórica, que assume valor 1 , se o Município recebeu pelo menos uma emenda no biênio anterior à fiscalização e 0 caso contrário e; (ii) a quantidade de recursos recebidos via emendas nos biênio anterior à fiscalização. 
O coeficiente de interesse $\alpha_{1}$ é associado à variável de emenda. Quando a variável categórica assume valor 1 se o Município i recebeu emenda e 0 no caso contrário, $\alpha_{1}$ expressa a diferença no nível de corrupção médio, fixadas as outras variáveis independentes. Quando a variável de emenda utilizada é a quantidade de recursos recebidos (em R $\$$ mil), $\alpha_{1}$ indica a variação quanto ao nível de corrupção médio, fixadas outras variáveis de controle, dado que um Município recebe $\mathrm{R} \$ 1.000$ a mais em emendas.

Controles corresponde a um vetor de variáveis sociodemográficas e políticas a saber: (i) população; (ii) Índice de Desenvolvimento Humano (educação e longevidade); (iii) Î́ndice de Gini; (iv) intensidade de pobreza; (v) percentual de pobres na população; (vi) renda per capita; (vii) percentual de votos válidos no primeiro turno das eleições do prefeito eleito; e (viii) um conjunto de variáveis categóricas, que assume valor 1 , se o prefeito é de determinado partido e 0 caso contrário. Desta forma, controla-se para os principais fatores sociodemográficos e político-partidários que podem afetar simultaneamente o recebimento de emendas (ou o seu valor) e o nível de corrupção.

A tabela 4 mostra os resultados dos modelos econométricos para a variável categórica de emenda. O coeficiente da variável de emendas na regressão com número de constatações como variável dependente é da ordem de 11,37, significativo a $1 \%$. De fato, o tamanho do coeficiente é bastante próximo daquele achado no exercício de diferenças de média (11,49 - Tabela 2).

Tabela 4

Modelo de Regressão Linear - Variável Categórica de Recebimento de Emendas e Quantidade de Recursos Transferidos via Emenda Parlamentar

\begin{tabular}{cccccc}
\hline \multicolumn{3}{c}{ Variável Dependente } & \multicolumn{3}{c}{ Variável Dependente } \\
\hline \multirow{2}{*}{$\begin{array}{c}\text { Constatações } \\
\text { (1) }\end{array}$} & Problemas & Problemas & Constatações & Problemas & Problemas \\
Administrativos & Graves & Admistrativos & Graves \\
& $(2)$ & $(3)$ & (4) & (5) & (6)
\end{tabular}

\begin{tabular}{|c|c|c|c|c|c|c|}
\hline $\begin{array}{l}\text { Variável Categorica } \\
\text { de recebimento de } \\
\text { emendas (Colunas (1)- } \\
\text { (3)) / Quantidade de } \\
\text { Emendas Recebidas } \\
\text { em R\$ mil (Colunas } \\
\text { (4)-(6)). }\end{array}$ & $(4,41)^{* * *}$ & $(1,18)^{* *}$ & $(2,49)$ & $(0,003)$ & $(0,0005)$ & $(0,001)$ \\
\hline População (milhares) & $\begin{array}{c}0,14 \\
(0,10)\end{array}$ & $\begin{array}{c}0,02 \\
(0,02)\end{array}$ & $\begin{array}{c}0,05 \\
(0.04)\end{array}$ & $\begin{array}{c}0,13 \\
(0.09)\end{array}$ & $\begin{array}{c}0,02 \\
(0,02)\end{array}$ & $\begin{array}{c}0,03 \\
(0,05)\end{array}$ \\
\hline IDH: Educação & $\begin{array}{l}-36.42 \\
(46,46)\end{array}$ & $\begin{array}{c}3,46 \\
(12,07)\end{array}$ & $\begin{array}{c}10,22 \\
(26,08)\end{array}$ & $\begin{array}{l}-34,09 \\
(47,32)\end{array}$ & $\begin{array}{c}3,54 \\
(12,42)\end{array}$ & $\begin{array}{c}11,92 \\
(26,43)\end{array}$ \\
\hline IDH: Longevidade & $\begin{array}{c}56,06 \\
(56,20)\end{array}$ & $\begin{array}{c}5,60 \\
(11,67)\end{array}$ & $\begin{array}{c}30,97 \\
(29,59)\end{array}$ & $\begin{array}{c}34,10 \\
(57,08)\end{array}$ & $\begin{array}{c}0,29 \\
(11,74)\end{array}$ & $\begin{array}{c}25,00 \\
(28,24)\end{array}$ \\
\hline Índice de Gini & $\begin{array}{c}4,25 \\
(53.80)\end{array}$ & $\begin{array}{c}0,61 \\
(13,70)\end{array}$ & $\begin{array}{l}-14,12 \\
(29.13)\end{array}$ & $\begin{array}{c}15,88 \\
(54,26)\end{array}$ & $\begin{array}{c}3,45 \\
(13,72)\end{array}$ & $\begin{array}{l}-11,01 \\
(28,43)\end{array}$ \\
\hline $\begin{array}{l}\text { Intensidade de } \\
\text { Pobreza }\end{array}$ & $\begin{array}{c}0,03 \\
(0,24)\end{array}$ & $\begin{array}{c}0,02 \\
(0,07)\end{array}$ & $\begin{array}{c}0,10 \\
(0,12)\end{array}$ & $\begin{array}{c}0,09 \\
(0,22)\end{array}$ & $\begin{array}{c}0,03 \\
(0,07)\end{array}$ & $\begin{array}{c}0,13 \\
(0,12)\end{array}$ \\
\hline $\begin{array}{l}\text { Percentual de Pobres } \\
\text { na População }\end{array}$ & $\begin{array}{c}0,66 \\
(0,45)\end{array}$ & $\begin{array}{c}0,15 \\
(0,12)\end{array}$ & $\begin{array}{c}0,27 \\
(0,29)\end{array}$ & $\begin{array}{c}0,44 \\
(0,45)\end{array}$ & $\begin{array}{c}0,10 \\
(0,11)\end{array}$ & $\begin{array}{c}0,20 \\
(0,27)\end{array}$ \\
\hline
\end{tabular}

Continua 


\section{Tabela 4 (continuação)}

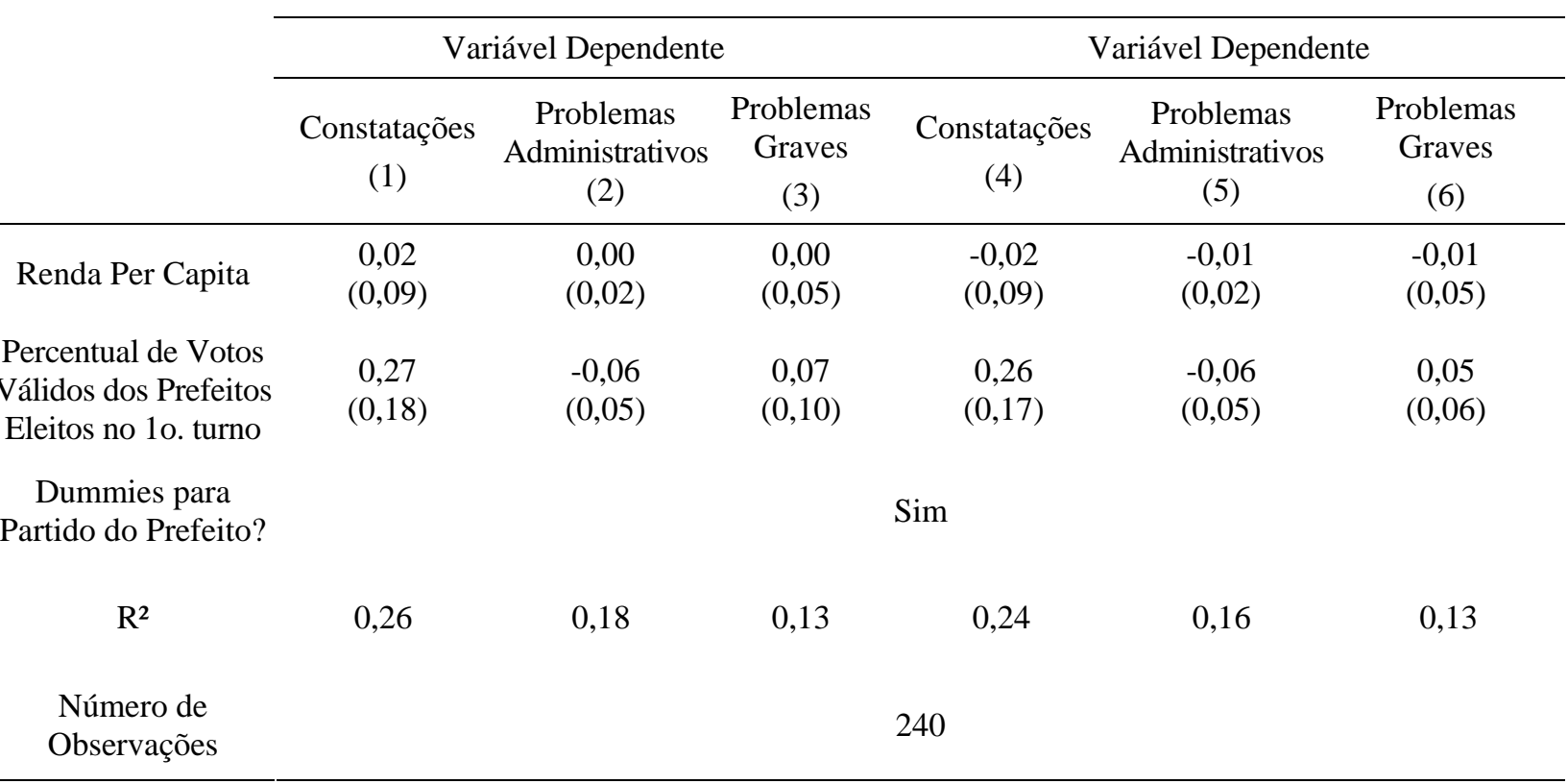

Nota. Fonte. Corrupção: fiscalizações de 03/2006 a 05/2007 (Controladoria-Geral da União. (2007). Relatórios de fiscalização de sorteios de municípios n 742 a 964. [Relatório Técnico]. Brasília: Secretaria Federal de Controle Interno. Recuperado em 11 novembro, 2007, de http://www.cgu.gov.br/sorteios/index1.asp). Emendas parlamentares: emendas à LOA em 2004 a 2006, sob modalidade de aplicação 40 (Senado Federal. (2008). LOA - 2005/2006/2007 - Execução de emendas por localidade. Brasília: Senado Federal. Recuperado em 5 fevereiro, 2008, de http://www8.senado.gov.br/businessobjects/enterprise115/desktoplaunch/InfoView/main/headerPlus.do?objId=0). Índice de Desenvolvimento Humano: 2000 (Programa das Nações Unidas para o Desenvolvimento. (2003). Atlas do desenvolvimento humano no Brasil - Municipal 1991 e 2000. [Relatório Técnico]. Brasília: PNUD. Recuperado em 5 fevereiro, 2008, de http://www.pnud.org.br/atlas/tabelas/). População: 2000 (Instituto Brasileiro de Geografia e Estatística. (2001). Censo demográfico 2000. [Relatório Técnico]. Rio de Janeiro: IBGE. Recuperado em 2 fevereiro, 2008, de http://www.ibge.gov.br/cidadesat/topwindow.htm?1). Renda per capita: 2004 e demais variáveis sociodemográficas: 2003 (Instituto Brasileiro de Geografia e Estatística. (2003). Mapa de pobreza e desigualdade - Municípios brasileiros - 2003. [Relatório Técnico]. Rio de Janeiro: IBGE. Recuperado em 2 fevereiro, 2008, de http://www.ibge.gov.br/cidadesat/topwindow.htm?1). Competições Políticas (Instituto Brasileiro de Geografia e Estatística. (2004). Representação política - 2004. [Relatório Técnico]. Rio de Janeiro: IBGE. Recuperado em 2 fevereiro, 2008, http://www.ibge.gov.br/cidadesat/topwindow.htm?1).

$*=$ significante a $10 \%, * *=$ significante a $5 \%$, ***=significante a $1 \%$. Todas as regressões contém uma constante. Erros-padrões robustos a heterocedasticidade reportados entre parênteses.

Isto indica que, mesmo controlando uma série de características municipais relevantes, Municípios que recebem emendas apresentam cerca de $25 \%$ a mais de constatações de irregularidade do que aqueles que não recebem recursos desta maneira. O coeficiente também é significativo estatisticamente para problemas graves; seu tamanho também é considerável. O mesmo não ocorre somente com problemas administrativos.

Isto significa que os problemas administrativos, relativos a falhas formais menos graves, não parecem ter relação com o recebimento de emendas. Já os problemas graves e constatações de irregularidades em geral demonstram relação com o recebimento de emendas parlamentares. Finalmente, a mesma tabela mostra que não existe relação estatisticamente significante entre a quantidade de recursos recebidos via emenda parlamentar e corrupção nos Municípios analisados, conforme já sugerido pela análise de diferenças de média.

Além disso, quando utilizamos como variável de emenda o volume de recursos liquidados, todos os coeficientes são bastante reduzidos. Por exemplo, o coeficiente de 0,0001 obtido na regressão com a variável dependente problemas graves indica que um aumento de R 1 milhão em emendas se associa, em média, ao crescimento no número de problemas em cerca de 0,1.

De maneira geral, tanto os testes de hipótese como as análises de regressão indicam que existe uma relação entre o nível de corrupção municipal e o recebimento de emendas parlamentares. Todavia a corrupção não parece aumentar linearmente com a quantia recebida de emendas. 
Caso o aumento da corrupção fosse gerado pelo aumento no ganho potencial do ato corrupto ou pelo aumento do poder discricionário local seria esperado que não somente o recebimento, mas o volume da transferência, fosse correlacionado com o número de irregularidades. Desta forma, os resultados empíricos deste estudo dão maior suporte as outras duas hipóteses levantadas: conluio com a corrupção federal e ação de grupos privados rent-seekers.

\section{CONSIDERAÇÕES FINAIS}

Este estudo defende que uma das causas que contribuem para o aumento da corrupção é a existência de transferências de recursos financeiros federais na forma de emendas parlamentares sem o devido controle sobre sua gestão, configurando grave falha institucional.

A análise empírica demonstra a existência de relação entre transferências intergovernamentais via emendas parlamentares e corrupção em Municípios brasileiros. Municípios que receberam recursos de emendas parlamentares apresentaram, em média, 25\% mais episódios de corrupção.

Embora o estudo não estabeleça, por meio das técnicas empregadas, uma relação causal entre emendas e corrupção, os resultados apontam a urgente e necessária ampliação da transparência e do controle sobre as aprovações e execuções de emendas parlamentares, sob pena de corroborar a persistência da corrupção no país e perpetuar a distorção de um dos principais instrumentos de descentralização de recursos aos governos locais.

A inexistência de accountability ou controle efetivo, com consequente aplicação de penalidades, enfraquece o ideal democrático do governo, acirra o descrédito social em relação à atuação do governo e impacta na sua governabilidade. Além disso, ao favorecer inescrupulosos e aqueles que dispõem de maior rede de contatos, a corrupção deforma os papéis alocativo e redistributivo do Estado.

Porém não há consenso, entre governantes ou estudiosos, quanto à melhor estratégia para combater esta situação. A análise das hipóteses explicativas apresentadas neste estudo, juntamente com os resultados empíricos, contribuem neste processo, uma vez que possibilitam uma avaliação de potencial efetividade das possíveis medidas a serem tomadas por meio da reflexão das hipóteses de relacionamento entre os fatores emenda e corrupção.

Os dados demonstram que o aumento da corrupção parece estar mais relacionado ao fato de um Município receber alguma emenda do que ao valor total das emendas repassadas a ele, mesmo quando este valor é considerado em termos per capita. Isto corrobora o pressuposto de que embora as emendas influenciem o grau de corrupção da gestão local, elas, por si sós, não a explicam em sua totalidade. Adicionalmente, esta constatação possibilita analisar as hipóteses de relacionamento entre corrupção e emendas parlamentares.

Dentre as quatro alternativas explicativas, não-excludentes entre si, de relacionamento entre emendas e corrupção, apresentadas neste estudo, os resultados empíricos parecem dar maior suporte a duas hipóteses explicativas levantadas: (iii) ação de grupos privados rent-seekers e (iv) conluio com a corrupção federal.

Por exemplo, se supomos que o aumento da corrupção advém de conluio com a corrupção federal, isto é, do fato de parlamentares corruptos escolherem Municípios com uma administração corrupta ou facilmente corruptível para serem os receptores de emendas, o simples fato de um Município ser selecionado para receber uma emenda já seria suficiente para ser observado, em média, um maior índice de corrupção. Este resultado independeria do valor efetivamente repassado.

Caso o aumento da corrupção fosse gerado (i) pelo aumento no ganho potencial do ato corrupto ou (ii) pelo aumento do poder discricionário local, seria esperado que não somente o recebimento, mas o volume da transferência fosse correlacionado com o número de irregularidades constatadas. 
Não obstante não competir a este estudo uma análise aprofundada das estratégias de controle existentes ou cabíveis, cabe pelo menos ilustrar a utilização dos resultados encontrados neste estudo para avaliação das alternativas de controle das emendas parlamentares. Por exemplo, o aumento da transparência em relação ao processo de proposição e aprovação das emendas seria grande auxílio no combate à pressão dos grupos rent-seekers, que atuam por meio de lobby no Congresso, e na dissolução de corrupções articuladas em nível federal, pois exporiam os agentes públicos ao controle por um maior número de instituições.

Outra estratégia de grande importância seria a fiscalização federal constante e concomitante da execução das emendas. Esta fiscalização deveria não somente analisar individualmente as emendas e seus instrumentos de execução, mas realizar cruzamentos de dados que permitissem a identificação de conluios por área de governo, tipo de gastos previstos, propositor da emenda no Congresso etc.

A breve análise dos resultados do estudo tende a inferir que a alternativa de capacitação de agentes públicos municipais não ataca tão diretamente o problema da corrupção via emendas parlamentares como as alternativas descritas acima. Isto porque esta solução se relaciona mais fortemente às hipóteses i e ii, não corroboradas pela análise empírica. Porém deve-se considerar que o estudo é limitado pela dificuldade de diferenciação precisa entre irregularidades de gestão e corrupção propriamente dita, ou seja, de atribuição de intencionalidade aos agentes. Neste sentido, a capacitação para o aprimoramento da gestão local pode ser entendida como uma das alternativas mais importantes de combate à corrupção no âmbito de governo local.

Não há estratégias única para o combate à corrupção, mesmo quando nos detemos num problema específico, como o caso da disvirtualização do instrumento de emendas parlamentares. Deter-se, porém, na análise pormenorizada de causas e relações com as estruturas e instituições de governo existentes facilita em muito a busca de alternativas com maior potencial de efetividade.

Por fim, cabe destacar outras análises pertinentes relacionadas ao tema, mas que fogem ao escopo deste estudo. Estas podem ser entendidas como uma indicação de agenda de possíveis estudos futuros. A primeira, citada apenas superficialmente neste estudo, é a discussão dos programas de controle de recursos em relação ao impacto e efetividade alcançados, o que depende, conforme argumentado, de um estudo mais aprofundado sobre os mecanismos da corrupção.

Outro estudo pertinente seria a superação da dificuldade de verificação da intencionalidade do agente, por meio de uma análise fenomenológica, de forma a separar constatações de má gestão pública daquelas de desvios e fraudes intencionais.

Artigo recebido em 01.12.2008. Aprovado em 09.06.2009.

\section{REFERÊNCIAS BIBLIOGRÁFICAS}

Bardhan, P. (1997). Corruption and development: a review of issues. Journal of Economic Literature, 35(3), 1320-1346.

Cartier-Bresson, J. (1998). Les analyses économiques des causes et des conséquences de la corruption: quelques enseignements pour les pays en développement. Mondes en Développement, 26(102), 2540.

Constituição da República Federativa do Brasil de 1988. (2007). Brasília. Recuperado em 5 agosto, 2007, de http://www.planalto.gov.br/ccivil_03/constituicao/constituiçao.htm

Controladoria-Geral da União. (2006). Manual operacional do programa de fiscalização a partir de Sorteios Públicos [Manual]. Brasília: Secretaria Federal de Controle. 
Controladoria-Geral da União. (2007). Relatórios de fiscalização de sorteios de municípios $n^{\circ} 742$ a 964. [Relatório Técnico]. Brasília: Secretaria Federal de Controle Interno. Recuperado em 11 novembro, 2007 de http://www.cgu.gov.br/sorteios/index1.asp

Elliott, K. A. (2002). A corrupção como um problema de legislação internacional: recapitulação e recomendações. In K. A. Elliott (Org.), A corrupção e a economia global. Brasília: UnB.

Ferraz, C., \& Finan, F. (2008). Exposing corrupt politicians: the effect of Brazil's publicly release audits on electoral outcomes. Quarterly Journal of Economics, 123(2), 703-745.

Instituto Brasileiro de Geografia e Estatística. (2001). Censo demográfico 2000. [Relatório Técnico]. Rio de Janeiro: $\quad$ IBGE. Recuperado em 2 fevereiro, 2008, de http://www.ibge.gov.br/cidadesat/topwindow.htm?1

Instituto Brasileiro de Geografia e Estatística. (2003). Mapa de pobreza e desigualdade - Municípios brasileiros - 2003. [Relatório Técnico]. Rio de Janeiro: IBGE. Recuperado em 02 fevereiro, 2008, de http://www.ibge.gov.br/cidadesat/topwindow.htm?1

Instituto Brasileiro de Geografia e Estatística. (2004). Representação política - 2004. [Relatório Técnico]. Rio de Janeiro: IBGE. Recuperado em 2 fevereiro, 2008, http://www.ibge.gov.br/cidadesat/topwindow.htm?1

International Organization of Supreme Audit Institutions. (2004). Guidelines for internal control for de public sector [Manual]. Bruxels: INTOSAL.

Johnston, M. (2002). Agentes públicos, interesses particulares e democracia sustentável: quando política e corrupção se unem. In K. A. Elliott (Org.), A corrupção e a economia global. Brasília: UnB.

Jos, P. H. (1993). Empirical corruption research: besides the (moral) Point? Journal of Public Administration Research and Theory, 3(3), 359-375.

Klitgaard, R. (1988). Controlling corruption. Berkeley: University of California.

Lambsdorff, J. (2005). Transparency international corruption perceptions index (CPI). Alemanha: Passau University.

Loureiro, M. R., Teixeira, M. A. C., \& Prado, O. (2008). Construção de instituições democráticas no Brasil contemporâneo: transparência das contas públicas. Revista Organização \& Sociedade, 15(47), 107119.

Mauro, P. (1995). Corruption and growth. Quarterly Journal of Economics, 11(3), 681-712.

O’Donnell, G. (1998). Horizontal accountability in new democracies. Journal of Democracy, 9(3), 112126.

O’Donnell, G. (2005). Horizontal accountability: the legal institucionalization of mistrust. In S. Mainwaring \& C. Welna (Orgs.), Democratic accountability in Latin America (34-54). New York, NY: Oxford.

Organização das Nações Unidas. (2003). Convenção das Nações Unidas contra a corrupção. Mérida, México: Escritório Contra Drogas e Crimes.

Pina, V., \& Torres, L. (2003). Reshaping public sector accounting: an international comparative view. Canadian Journal of Administrative Sciences, 20(4), 334-350.

Pires, J. A. M., Jr. (2005). A realização orçamentária e financeira de emendas orçamentárias e o seu controle pelo executivo por meio da (in)fidelidade parlamentar. Monografia, Escola de Administração Fazendária, Brasília, DF, Brasil. 
Programa das Nações Unidas para o Desenvolvimento. (2003). Atlas do desenvolvimento humano no Brasil - Municipal 1991 e 2000. [Relatório Técnico]. Brasília: PNUD. Recuperado em 5 fevereiro, 2008, de http://www.pnud.org.br/atlas/tabelas/

Rose-Ackerman, S. A. (2002). Economia política da corrupção. In K. A. Elliot (Org.), A corrupção e a economia global. Brasília: UnB.

Secretaria do Tesouro Nacional. (2006). Manual técnico do orçamento [Manual]. Brasília: Secretaria do Orçamento Federal. Última atualização em 27 de junho, 2006.

Senado Federal. (2008). LOA - 2005/2006/2007 - Execução de emendas por localidade. Brasília: Senado Federal. Recuperado em 5 fevereiro, 2008, de http://www8.senado.gov.br/businessobjects/enterprise115/desktoplaunch/InfoView/main/headerPlus. do?objId $=0$

Treisman, D. (2000). The causes of corruption: a cross-national study. Journal of Public Economics, 76(3), 399-457.

Weber, L. A. (2006). Capital social e corrupção municipal. Dissertação de mestrado, Universidade de Brasília, DF, Brasil.

Zambioni, Y., Filho, \& Litschig, S. (2006). Law Enforcement and Local Governance in Brazil: evidence from random audit reports [Working Paper]. Columbia University, New York, NY. 